UC-902

Issued: November 1994

A Compendium of Results from Long-Range Alpha Detector Soil Surface Monitoring:

June 1992 - May 1994

S. E. Garner

J. A. Bounds

K. S. Allander

R. W. Caress*

J. D. Johnson

D. W. MacArthur 


\section{Contents}

1. INTRODUCTION

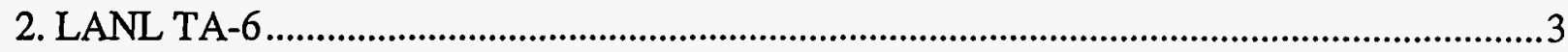

3. FERNALD SEWAGE-TREATMENT PLANT .................................................................

4. FERNALD DECONTAMINATION AND DECOMMISSION (D\&D) AREA ......................5

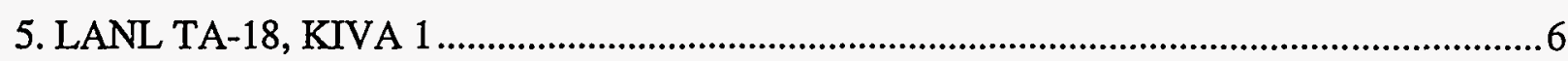

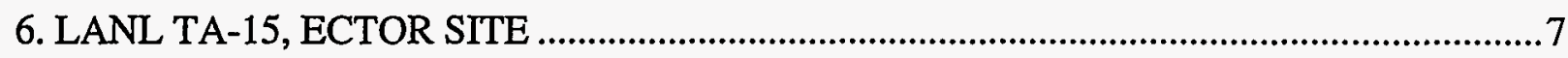

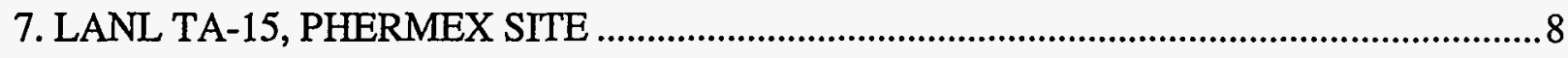

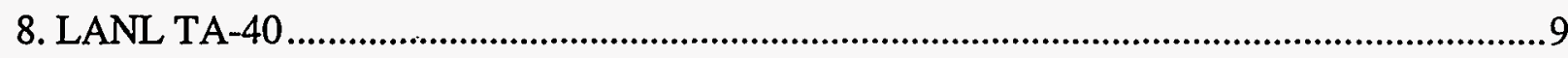

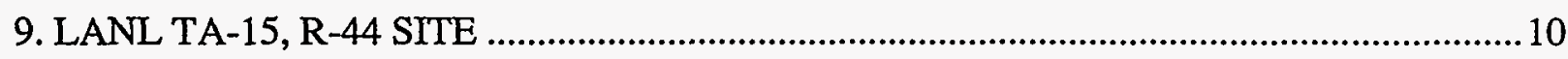

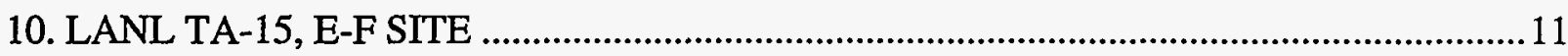

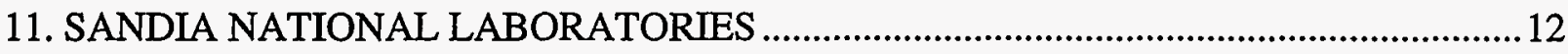

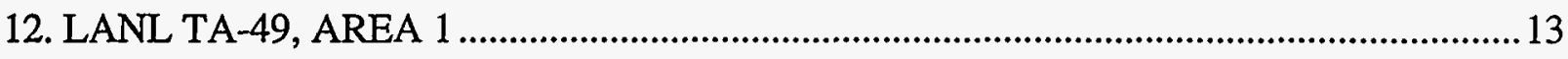

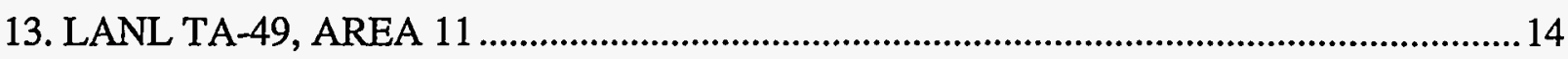

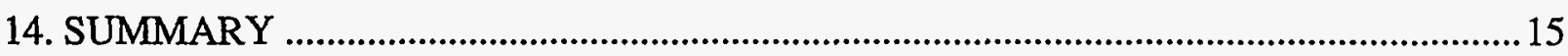

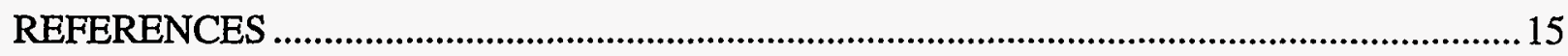




\section{DISCLAIMER}

This report was prepared as an account of work sponsored by an agency of the United States Government. Neither the United States Government nor any agency thereof, nor any of their employees, make any warranty, express or implied, or assumes any legal liability or responsibility for the accuracy, completeness, or usefulness of any information, apparatus, product, or process disclosed, or represents that its use would not infringe privately owned rights. Reference herein to any specific commercial product, process, or service by trade name, trademark, manufacturer, or otherwise does not necessarily constitute or imply its endorsement, recommendation, or favoring by the United States Government or any agency thereof. The views and opinions of authors expressed herein do not necessarily state or reflect those of the United States Government or any agency thereof. 


\section{DISCLAIMER}

Portions of this document may be illegible in electronic image products. Images are produced from the best available original document. 


\title{
A COMPENDIUM OF RESULTS FROM \\ LONG-RANGE ALPHA DETECTOR SOIL SURFACE MONITORING: \\ JUNE 1992 - MAY 1994
}

by

\author{
S. E. Garner, J. A. Bounds, K. S. Allander, R. W. Caress, J. D. Johnson, and \\ D. W. MacArthur
}

\begin{abstract}
Soil surface monitors based on long-range alpha detector (LRAD) technology are being used to monitor alpha contamination at various sites in the Department of Energy complex. These monitors, the large soil-surface monitor (LSSM) and the small soil-surface monitor (SSSM), were used to help characterize sites at Fernald, Ohio, and active or inactive firing sites at Sandia National Laboratories and Los Alamos National Laboratory. Monitoring results are presented herein in chronological order.
\end{abstract}

\section{INTRODUCTION}

A new technology to monitor surface soil for alpha particle contamination is being proven at Department of Energy sites around the country. Long-range alpha detection (LRAD) technology represents substantial improvements in sensitivity, durability, and speed over traditional alpha detection technologies. The LRAD technology has been presented elsewhere. ${ }^{1}$ The results to date are compiled here.

The LRAD Large Soil Surface Monitor (LSSM), which is shown in Figure 1, is like all
LRADs: it does not detect alpha particles directly, as do traditional monitors, but detects the ions that alpha particles create in ambient air as they lose energy. This novel approach gives LRAD-based technology a tremendous advantage over traditional alpha detection methods because the ions created by the alphas can be transported great distances from the source (up to many meters). Conversely, for a traditional alpha detector to work, it must be placed within a few centimeters of the source because an alpha's range in air is very limited. This difference allows the LSSM to interrogate large, uneven surfaces, and, because

Fig. 1. The large soil-surface monitor (LSSM) mounted to a tractor.

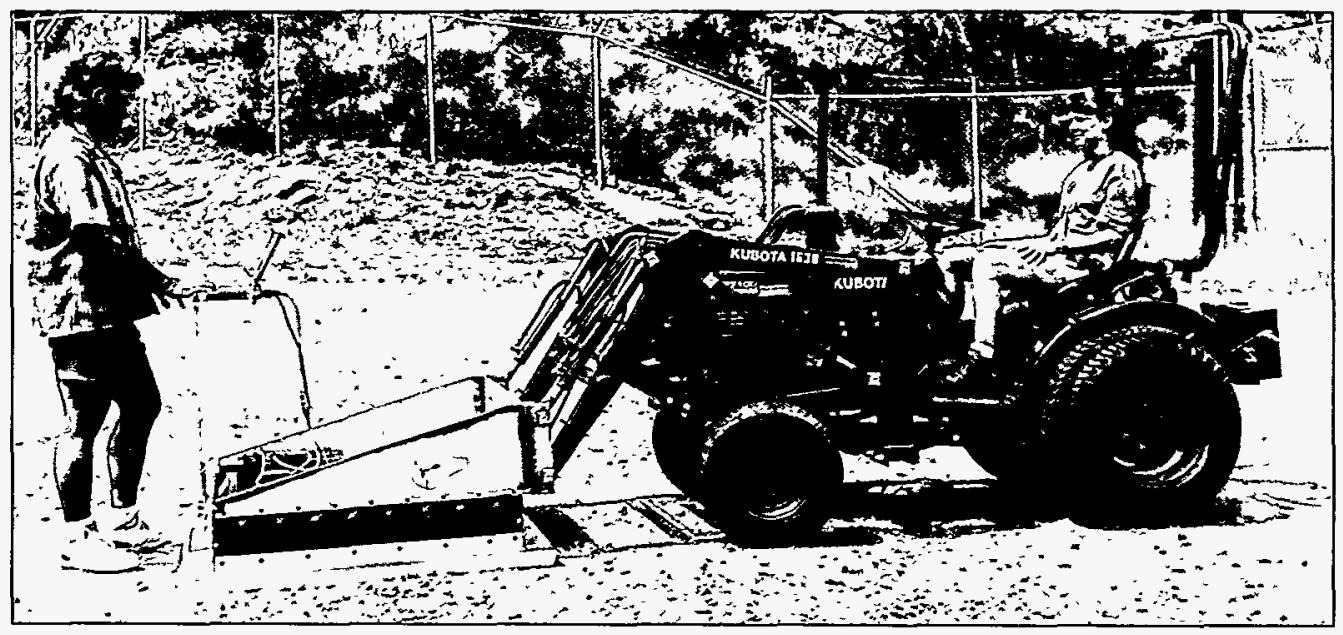




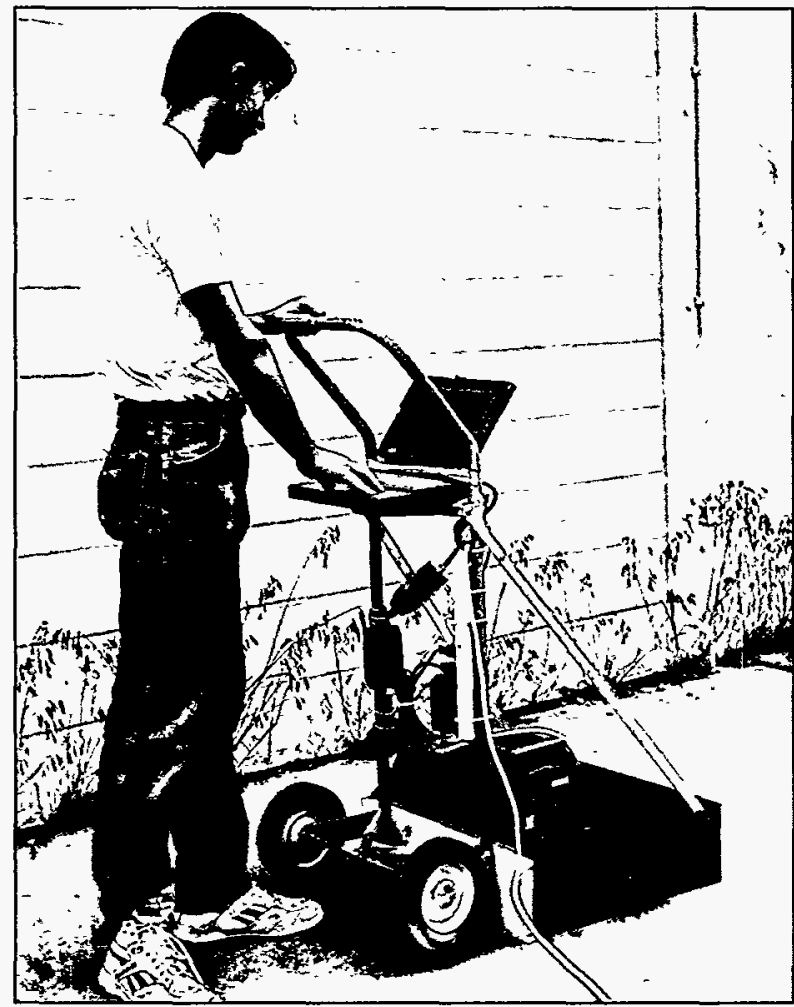

Fig. 2. The small soil surface monitor (SSSM).

data acquisition for the LSSM is completely automated, the results are not influenced by the interrogating techniques of the operator, a factor that often puts traditional alpha detector results in question.

The soil surface monitor can detect alpha contamination to a soil depth of $36 \mu \mathrm{m}$. Although beta particles also produce ions, LRAD technology is over 100 times more sensitive to alpha than beta particles. This fact was confirmed in field tests. The weak response to beta sources during testing assured that the response of the LSSM is due almost entirely to alpha-emitter contamination.

The LSSM is a $1-\mathrm{m}^{2}$ open-bottomed box that is placed face-down on the soil surface. Alphacontamination on the soil surface emits alpha particles into the air, where ions are created. The LSSM collects these ions, thereby detecting the alpha particles that created them. Because the LSSM was engineered to be very rugged, it is heavy $(-300 \mathrm{lb})$ and is mounted on the loader of a small tractor. In this configuration it can be transported over and used on rugged terrain. Because it is sturdy, the LSSM can be used in the field with little chance that the detector components will be damaged. In the unlikely event that damage does occur, its design is so simple that repairs can be made by the operators in the field. This feature is in sharp distinction to some traditional monitors, which incorporate a thin Mylar window or thin wires that are easily damaged and are difficult and expensive to replace.

With the LSSM, the preliminary analysis of soil monitoring data is performed as the data are collected. Therefore, results from large sites can be obtained very quickly. The LSSM requires $\sim 10$ minutes to collect data for one point. At this rate, sites of approximately 10 acres have been monitored in less than a week. Final results can be returned in as little as one or two days after the monitoring is completed. This turn-around time represents a great improvement over the months spent waiting for the results from the laboratory analysis of soil samples using older methods.

The small soil surface monitor (SSSM), pictured in Figure 2, is a $0.25-\mathrm{m}^{2}$ version of the LSSM. Like the LSSM, it is a rugged, fieldable detector capable of giving results in near real-time.

The LSSM and the SSSM were used to monitor soil surfaces at several sites around Los Alamos National Laboratory (LANL), Sandia National Laboratories (SNL), and the Fernald Environmental Management Project in Fernald, Ohio. In addition, several different surface monitors were recently calibrated on concrete pads provided for this purpose in Grand Junction, Colo., and Grants, N.M. These calibrations showed that the levels of soil surface alpha-emitter contamination extrapolated from LSSM and SSSM data are accurate representations of the true amounts of alpha activity. This finding is further supported by laboratory analysis of soil samples taken from the sites monitored in Fernald.

LRAD results from all of the sites monitored through May 1994 are given in the pages that follow, along with a brief description of the site and an interpretation of the data. 


\section{LANL TA-6}

\section{Site Description}

The asphalt blasting pad at TA- 6 was used for explosives testing during the Manhattan Project. It has been left idle during most of the time since then. The asphalt, which is beginning to deteriorate, is broken up, and vegetation is beginning to grow through the cracks. The edges of the pad are somewhat undefined because they are covered over with dirt. The pad is roughly $12 \mathrm{~m}$ by $18 \mathrm{~m}$ and has a small concrete pit $60 \mathrm{~cm}$ wide by $150 \mathrm{~cm}$ long by $60 \mathrm{~cm}$ deep. Only half the pad is shown in Fig. 3. It is believed that the pit was used in implosion tests as a catch pan. It is now filled with pieces of wood and metal. Some of the concrete appears to have been chiseled away, perhaps in attempts to remove contamination. Other debris at the site include a rectangular piece of metal, which might have been a cover plate for the catch pan, and a round, heavily dented piece of metal.

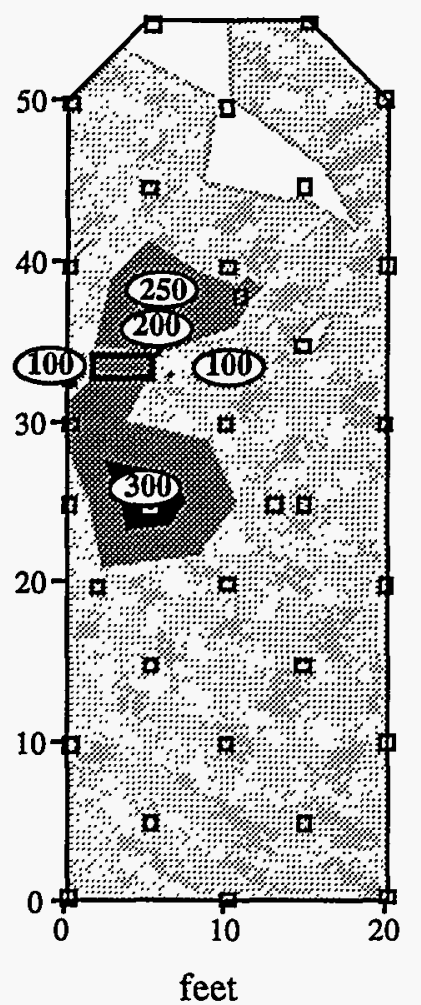

\section{Results}

No site preparation was necessary. To determine how contamination is distributed on the pad, we took a set of readings at 3-m intervals along each of several rows. The rows were spaced $1.5 \mathrm{~m}$ apart, and the data collection points were staggered $1.5 \mathrm{~m}$ from row to row, making a pattern similar to a "five-spot" on dice. In addition to the grid points, we also took supplemental measurements in areas of special interest: the metal cover plate, the circular metal plate, and several points near the pit. The detector required $\sim 10$ minutes per data point. Figure 3 shows the results of the scan with the SSSM. The computer graphics program DeltaGraph Pro for the Macintosh interpolated between the points, producing the gray-scale contour plot. The sample points with the highest readings were also monitored with a Ludlum-139 hand-held alpha probe. The concrete catch pan was too small for the SSSM to measure inside so the Ludlum monitor was used. No detectable contamination was present there.

\section{Interpretation}

The hot spots found with the SSSM produced responses in the Ludlum that were scarcely above background. The results from measurements taken with the Ludlum are shown in the plot as numbers printed on top of the spot where the measurement was taken. Numerically, the two methods do not agree, but they give results that are in rough proportion to each other. This should not come as a surprise, considering that the SSSM has an area of 2,500 $\mathrm{cm}^{2}$ and the Ludlum-139 has an area of only $80 \mathrm{~cm}^{2}$. (For reference, normal background is between 100 and $300 \mathrm{dpm} / 100 \mathrm{~cm}^{2}$, and the DOE release limit for transuranics is $300 \mathrm{dpm} / 100 \mathrm{~cm}^{2}$.) 


\section{FERNALD SEWAGE-TREATMENT PLANT}

\section{Site Description}

The sewage-treatment plant (STP) area at Fernald is a 9-acre field that encompasses the sewage treatment plant and incinerator facility. The area immediately surrounding the STP and incinerator was not monitored, it was inside a fence. The incinerator is not in use at this time. Site preparation was limited to cutting the indigenous vegetation to ground level and raking it away immediately before monitoring. The STP area terrain is somewhat rolling with occasional tire ruts $\sim 10 \mathrm{~cm}$ deep. A grid of data points, each $18.3 \mathrm{~m}$ apart, was laid out. Some of the planned sample points were inaccessible because of terrain features. Others were covered with water or were too muddy for monitoring. These points were skipped. A weedeater-type cutter was used to clear any vegetation prior to placement of the detector. Vegetation interferes with measurements in two ways: a blade of grass can cause a shortcircuit between the signal plane and the soil, creating currents that are orders of magnitude greater than those due to alpha particles, and vegetation can shield the detector from the alphaemitter activity beneath it.

\section{Results}

Figure 4 shows the results of the LSSM scan at the STP site. Again, DeltaGraph Pro for the Macintosh was used to interpolate between the data points and to create the gray-scale plot. The large square hatched area represents the fenced-in area of the STP and was not monitored. Neither was the small attached rectangular area, which is the access road. Each data point required 15 minutes for the detector to settle on a reading. Temperatures were in the $80 \mathrm{~s}$ and $90 \mathrm{~s}$ with relative humidities over $80 \%$. Because this was the first use of the LSSM, one of the points was measured several times daily to watch for variations and to check for reproducibility.

\section{Interpretation}

The large area of contamination located at
$(9,12)$ is most likely due to ash fallout from the incinerator stack. The other "hotter" areas at $(4,8)$ and $(8,3)$ correspond to known leaks from within the sewage treatment plant. The hot spot on the bottom edge of the STP area at $(4,1)$ is a previously known spot of contamination whose source is unknown. The "hot" territory spanning the area between $(1,3)$ and $(4,3)$ was previously unknown, but measurements were taken there repeatedly and the confidence of its existence is high. We interpret the cold area around $(5,3)$ as being caused by the clean gravel spread over the surface to form a parking area. Similarly $(6,1)$ was covered the older, dirty gravel. The large cool area around (2-3,9-10) corresponds to a wet, swampy part of the site. The water could have been covering up some of the contamination, or running water could have dispersed the uranium. The spots monitored were near the swampy area but were dry when monitored. We attempted to compare our results with those obtained with both Ludlum-139 and Eberline traditional portable alpha detectors. None of the contamination at the STP site was detectable with either portable alpha instrument.
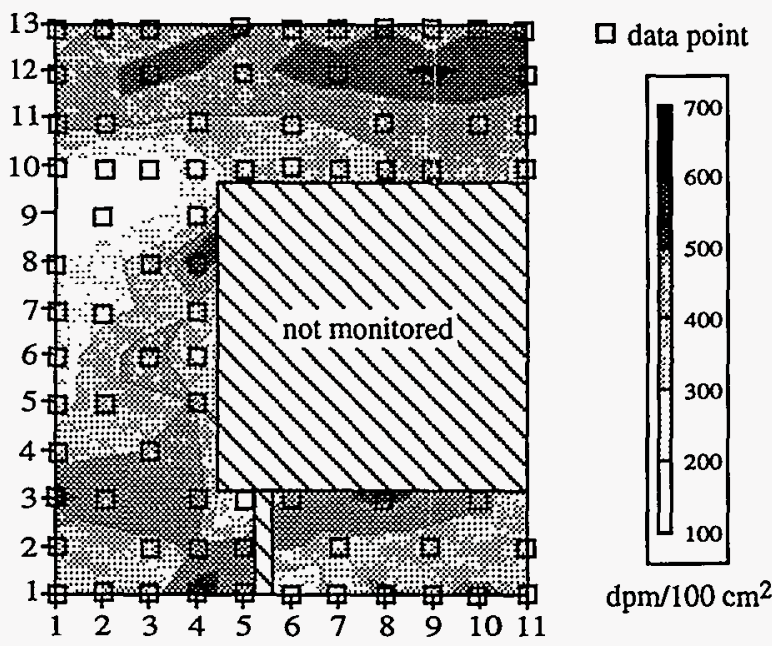

Fig. 4. Fernald sewage-treatment plant area. 


\section{FERNALD DECONTAMINATION AND DECOMMISSION (D\&D) AREA}

\section{Site Description}

The D\&D area, a $~ 2.5$-acre field, is one of the more contaminated areas within the Fernald boundary. The vegetation here is somewhat less uniform than at STP, with pieces of metal randomly spread about and slag in many places. The vegetation was removed down to soil level and then raked away before placement of the detector. The area is mostly flat, with a roadbed and railroad line being the only features of note. Anticontamination equipment, including coveralls, booties and gloves, was required for all workers in the $D \& D$ area. Again, data points were set $18.3 \mathrm{~m}(60 \mathrm{ft})$ apart. The irregular hatched area was neither gridded nor monitored. Some data points were not measured because of topography or time constraints.

\section{Results}

Figure 5 was created using the data collected from the D\&D area. This is the hottest area ever monitored by the LRAD LSSM.

\section{Interpretation}

The area around $(2,7)$ that has relatively more contamination is already known to Fernald personnel. The area of extreme contamination near $(2,2)$ has also been previously identified by Fernald. An unspecified barrel was spilled there once. Some pieces of metal strewn near $(2,2)$ may have also contributed to the contamination level indicated by the detector. There is no explanation for the contamination that runs along the border of the monitored site from $(8,8)$ to $(4,5)$. The area along the upper edge of the site that shows relatively low contamination is covered by a roadbed. It is possible that the roadbed is covering contamination that would have otherwise been seen by the detector.

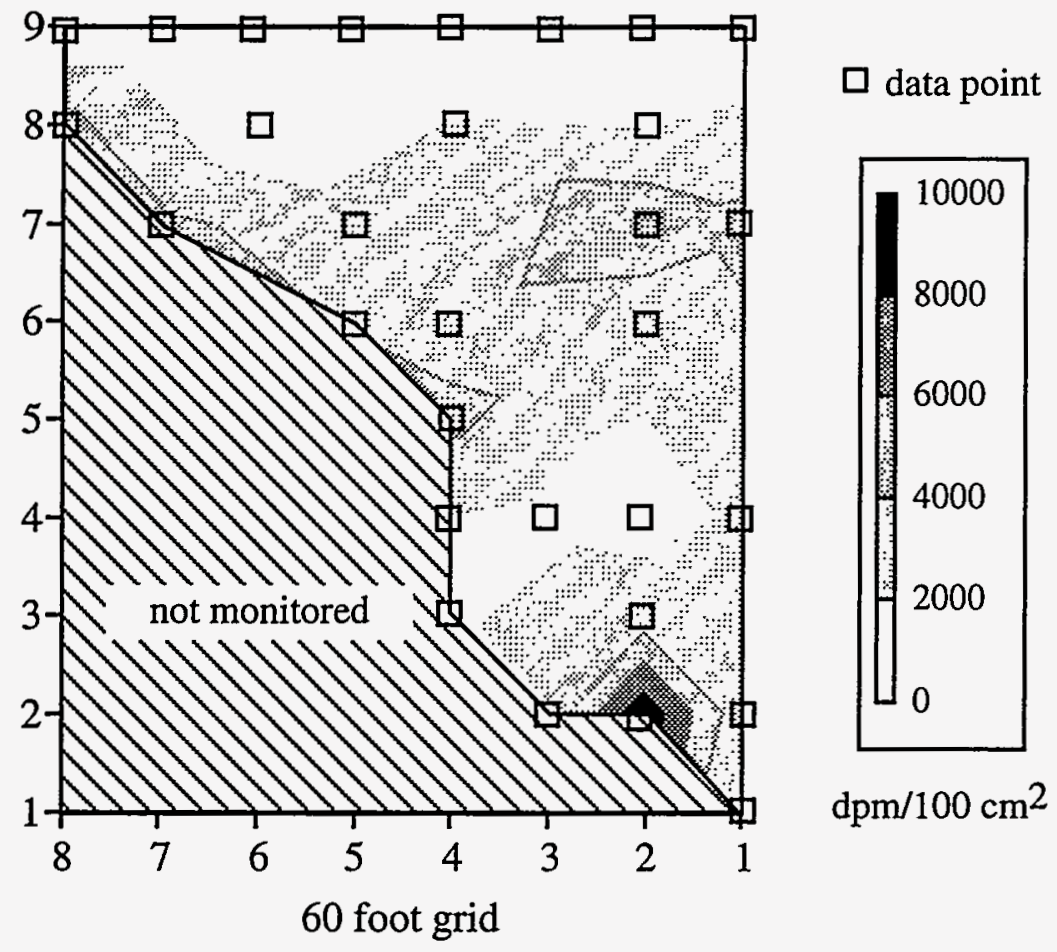

Fig. 5. Fernald $D \& D$ site. 


\section{LANL TA-18, KIVA 1}

\section{Site Description}

Kiva 1 is one of the three areas at Los

Alamos where reactor experiments still take place. Kiva 1 is located immediately adjacent to a small building that houses the SHEBA (solution highenergy burst assembly) reactor. The entire site is ringed with a fence and much of the area inside has been covered with asphalt. The history of the site is somewhat sketchy, but apparently it had been used been used for some limited explosives tests. These tests are said to have taken place before there was any depleted uranium in existence.

\section{Results}

The detector required only $\sim 5$ minutes per data point. Figure 6 was created using the data collected from the Kiva 1 area.

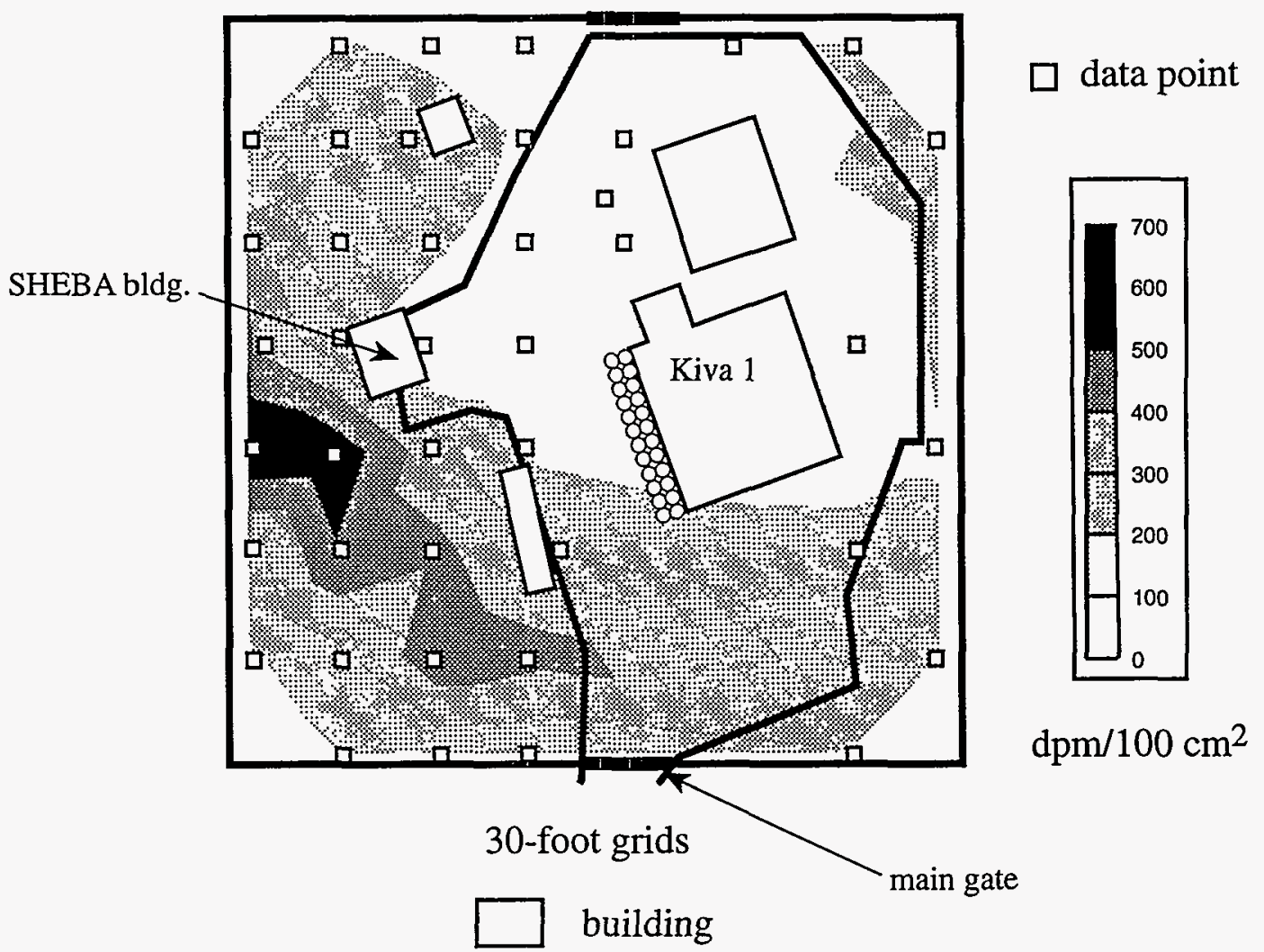

Fig. 6. LANL, TA-18, Kiva 1. 


\section{LANL TA-15, ECTOR SITE}

\section{Site Description}

Ector site is one of several facilities at TA-15 used to study the performance of explosives. Ector has been in use since the mid-1980s for dynamic radiography of explosion-driven weapons components. After larger tests at this site, the dirt nearest the firing point was removed, and "clean" soil fill was put in its place. This was done to keep the soil contamination levels around the firing point at or near background. The site is approximately 250 feet by 150 feet with terrain varying from flat with no vegetation near the firing point to broken with heavy vegetation around the western and southern perimeters.

\section{Results}

The response time of the detector at Ector site was $\sim 10$ minutes per point. A weedeater-type trimmer was used to clear sample points of vegetation for detector placement. We used the data collected at the Ector site to create the chart shown in Figure 7. The squares indicate points where data were taken. A computer interpolated between the points, producing the gray-scale contour plot.

\section{Interpretation}

It should be noted that there are several spots that were considerably more contaminated than the surrounding soil. These are denoted by black squares. These spots were not included in the data for interpolation. Because these points are so much hotter than everything nearby, they would have skewed the resulting plot and not given a realistic view of the site. We believe that what is shown is the best representation of the contamination that is really present.

As expected, the soil that is not indigenous to the site is at or near background level. The border between the indigenous soil and "clean" soil was drawn in before any data analysis took place. It follows the edge of the hotter zones well.

The hot spot $\left(1150 \mathrm{dpm} / 100 \mathrm{~cm}^{2}\right)$ near point

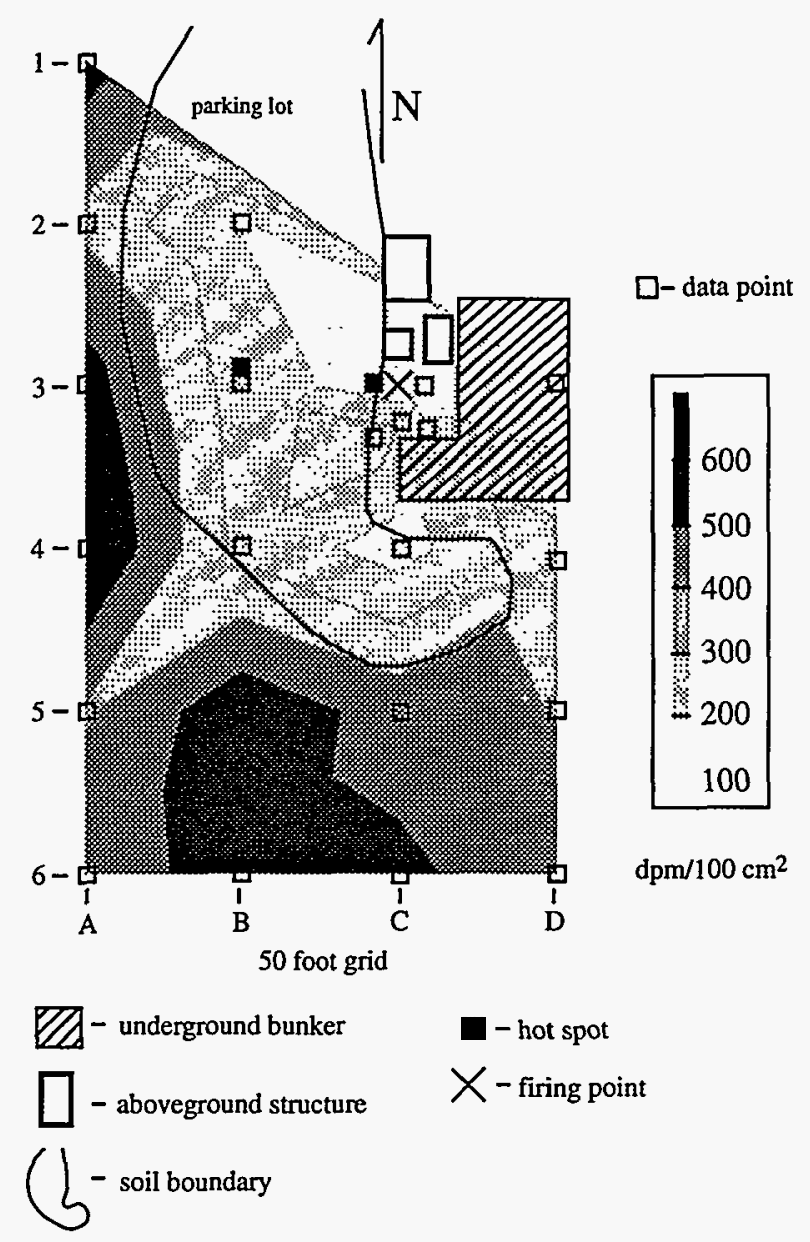

Fig. 7. LANL, TA-15, Ector site.

B3 is due to the presence of a chunk of uranium embedded on the soil surface. Since this contamination is from a point source, not a uniform soil distribution, the level of activity of the part of the chunk exposed is around 90,000 dpm.

The hot spot $7 \mathrm{ft}$ west and $1 \mathrm{ft}$ north of $\mathrm{C} 3$, the firing point, measured $600 \mathrm{dpm} / 100 \mathrm{~cm}^{2}$. A hot spot (not shown in the chart) immediately to the north of the firing point measured $1600 \mathrm{dpm} /$ $100 \mathrm{~cm}^{2}$ and a point immediately south (also not shown) of the firing point measured $1100 \mathrm{dpm} /$ $100 \mathrm{~cm}^{2}$. That these three points all showed elevated contamination levels is probably due to their close proximity to the firing point.

The detector was placed against one of the vertical steel barriers placed a few feet north of the firing point. In this location the detector measured $4000 \mathrm{dpm} / 100 \mathrm{~cm}^{2}$. 


\section{LANL TA-15, PHERMEX SITE}

\section{Site Description}

PHERMEX (pulsed, high-energy, radiographic machine-emitting $\mathrm{x}$ rays) site is also located at TA-15 and has been used in much the same fashion as the Ector site. It has been used for approximately 30 years. The amounts of uranium now used are less than $1000 \mathrm{~kg}$ per year. The terrain of the area monitored ranged from flat and gravel-covered near the firing point to more broken with considerable vegetation near the southern and western perimeters of the site (Fig. 8). There were several chunks of depleted uranium sitting on the ground near the firing point. An effort was made to ensure that none of these chunks was under the detector during a monitoring session. In addition to monitoring with the LSSM, samples were also placed inside a smaller soil sample monitor similar to the soil surface monitor described above. These samples came from points in and near the trench dug for the future installation of Ector.

\section{Results}

The response time of the detector at PHERMEX was less than 10 minutes per point. A weedeater-type trimmer was again used to clear vegetation from the spot to be monitored, where necessary. The data collected at the PHERMEX site were used to create the chart in Figure 8. The results from the samples taken in and around the trench are presented in Reference 2. To determine whether the lack of heavy contamination of the surface soil was due to a downward migration of the uranium, we took a small amount of soil and placed it in an LRAD sample monitor. Although the sample removed included soil that came from a depth considerably greater than $36 \mu \mathrm{m}$, the sample monitor results were essentially the same as the surface monitor results.

\section{Interpretation}

There is one spot at PHERMEX where the detector saw very elevated levels of contamination. This spot coincided with the firing point. This point was not included in the resulting interpola- tion for the same reason it was ignored at the Ector site: it would skew the contour plot.

The hot spot at the firing point had a contamination level of $10,000 \mathrm{dpm} / 100 \mathrm{~cm}^{2}$. A chunk of depleted uranium was placed underneath the detector after measuring a point $25 \mathrm{ft}$ northnortheast of point $\mathrm{F} 0$. The level of activity of this chunk was over $100,000 \mathrm{dpm}$.

The lines on the chart in the "steep area" are contour lines. The space between two lines represents a change in elevation of $4 \mathrm{ft}$, where the northern part of the steep area is above the southern. The area was too steep to monitor.

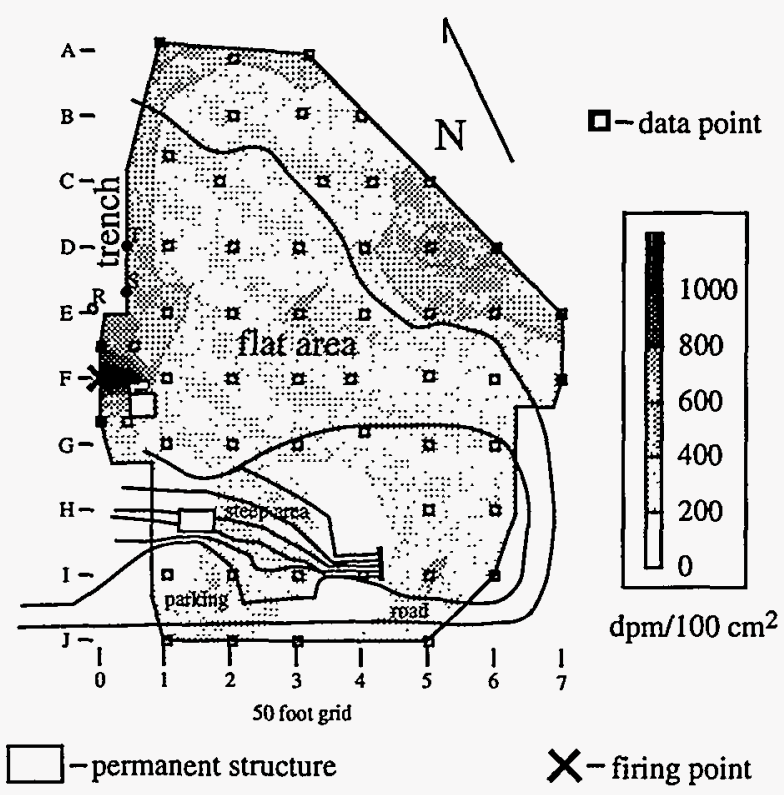

Fig. 8. LANL, TA-15, PHERMEX site. 


\section{LANL TA-40}

\section{Site Description}

The area known as TA-40 Chamber 4 is a smaller blasting area $\left(7000 \mathrm{ft}^{2}\right)$ designed to handle up to $25 \mathrm{lb}$ of high explosives. There are reports of very limited uranium use in the distant past. The chamber is on an outcropping of a canyon wall with the southern edge dropping off into the canyon. The soil is a sand/gravel mixture that does not appear to have been there before the existence of the site.

\section{Results}

A close spacing (only $15 \mathrm{ft}$ ) was used because we were trying to find any uranium rather than map the spread of contamination. The response time of the detector was about 10 minutes per data point. The data collected at TA-40 Chamber 4 were used to create the plot shown in Figure 9.

\section{Interpretation}

With the possible exception of a few shots years ago, there is no clear record that firing tests at Chamber 4 used uranium. This evidence is supported by the low contamination levels (at or below background of about $200 \mathrm{dpm} / 100 \mathrm{~cm}^{2}$ ) measured at every data point on the site.

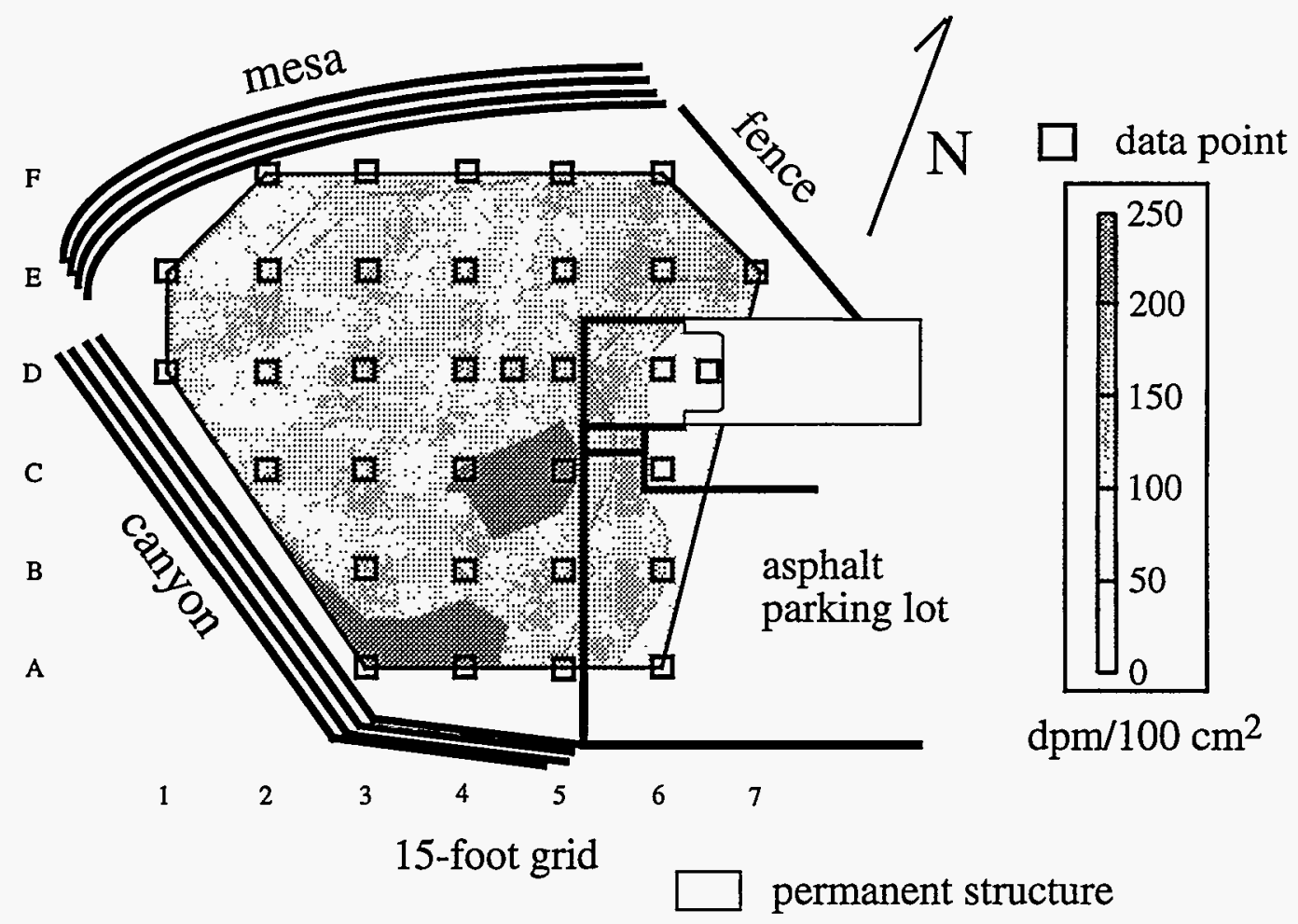

9

Fig. H. LANL, TA-40, Chamber 4 


\section{LANL TA-15, R-44 SITE}

\section{Site Description}

One of the inactive firing sites to be surveyed at TA-15 is the area designated R-44. This firing site was built in 1951 and was used extensively from 1956 to 1978 for diagnostic tests for weapons components. Approximately $7000 \mathrm{~kg}$ of depleted uranium were used here. Since the two currently been used for small experiments. R- 44 is 80 feet by 120 feet, less than $10,000 \mathrm{ft}^{2}$. The site's close proximity to a canyon edge made disposal of contaminated soil easy. Soil was bulldozed over the edge and allowed to fall into the canyon. active sites were put into operation, $\mathrm{R}-44$ has only

\section{Results}

The response time of the detector was about 10 minutes per data point. The data collected at R-44 were used to create the plot shown in Figure 10 . Some yellowcake was seen on the soil surface, but no soil containing visible amounts of yellowcake were monitored.

\section{Interpretation}

$R-44$ showed varying levels of activity. The small scale of the site and the bulldozed soil has generated a seemingly random distribution of activity. The presence of yellowcake visible in scattered areas at this site supports this observation. A wider survey would be enlightening.

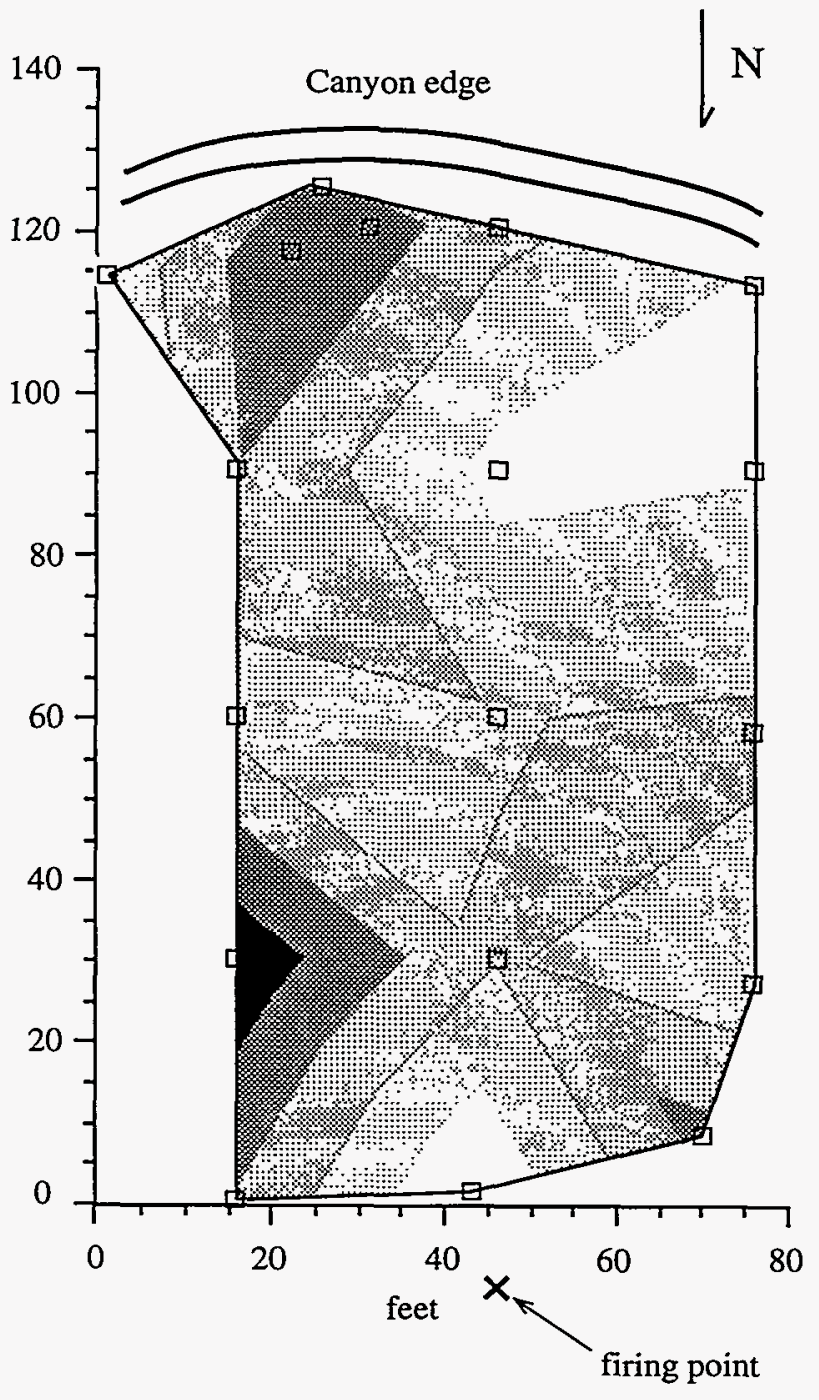

$\square$ data point

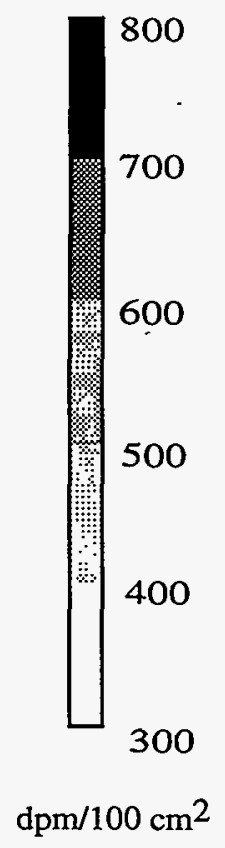

Fig. 10. LANL, TA-15, R-44 site. 


\section{LANL TA-15, E-F SITE}

\section{Site Description}

Though E-F Site is currently inactive, it was the most heavily used firing site at Los Alamos, both in terms of active use (1947-1981) and the size of individual explosions (up to $2500 \mathrm{lb}$ ). Initially, natural uranium was used in these tests, but after 1957, it was replaced by depleted uranium. In all, about $43,000 \mathrm{~kg}$ of natural uranium and $20,000 \mathrm{~kg}$ of depleted uranium were used here. Most of this uranium is thought to be still located in the soil, since the main pathways for uranium migration (aerosolization and hydrologic runoff) are fairly minor. Because of the relatively large amounts of explosives used here, the site is much bigger than most of the other firing sites. For the same reason, the size of the area thought to be potentially contaminated is much greater $\left(\sim 800,000 \mathrm{ft}^{2}\right)$. The tests were done to determine the performance of weapons components. The site is $1,500 \mathrm{ft}$ by 1,100 feet.

\section{Results}

Approximately 10 minutes were required per data point at E-F Site. The data from E-F Site are plotted and displayed in Figure 11. Both LSSMs were used for monitoring with no discrepancies. Temperatures ranged from just above freezing to $60^{\circ} \mathrm{F}$. There was no significant change in the readings.

\section{Interpretation}

E-F Site shows much higher contamination levels than the other firing sites. The effects of weathering and settling do not seem to have changed the amount of contamination very much. As at other firing sites, bits of uranium were seen on the soil surface. There are two earthen mounds located near the firing point that seem to have shielded the ground behind them from flying contamination. A drainage ditch in the northwest part of the site does show elevated contamination levels, probably due to the migration of uranium because of runoff. The relative high and constant values of uranium concentration in this drainage ditch were confirmed with soil samples taken here. Little contamination reached the canyon edge to the south due to the barrier mound between the edge and the firing point.

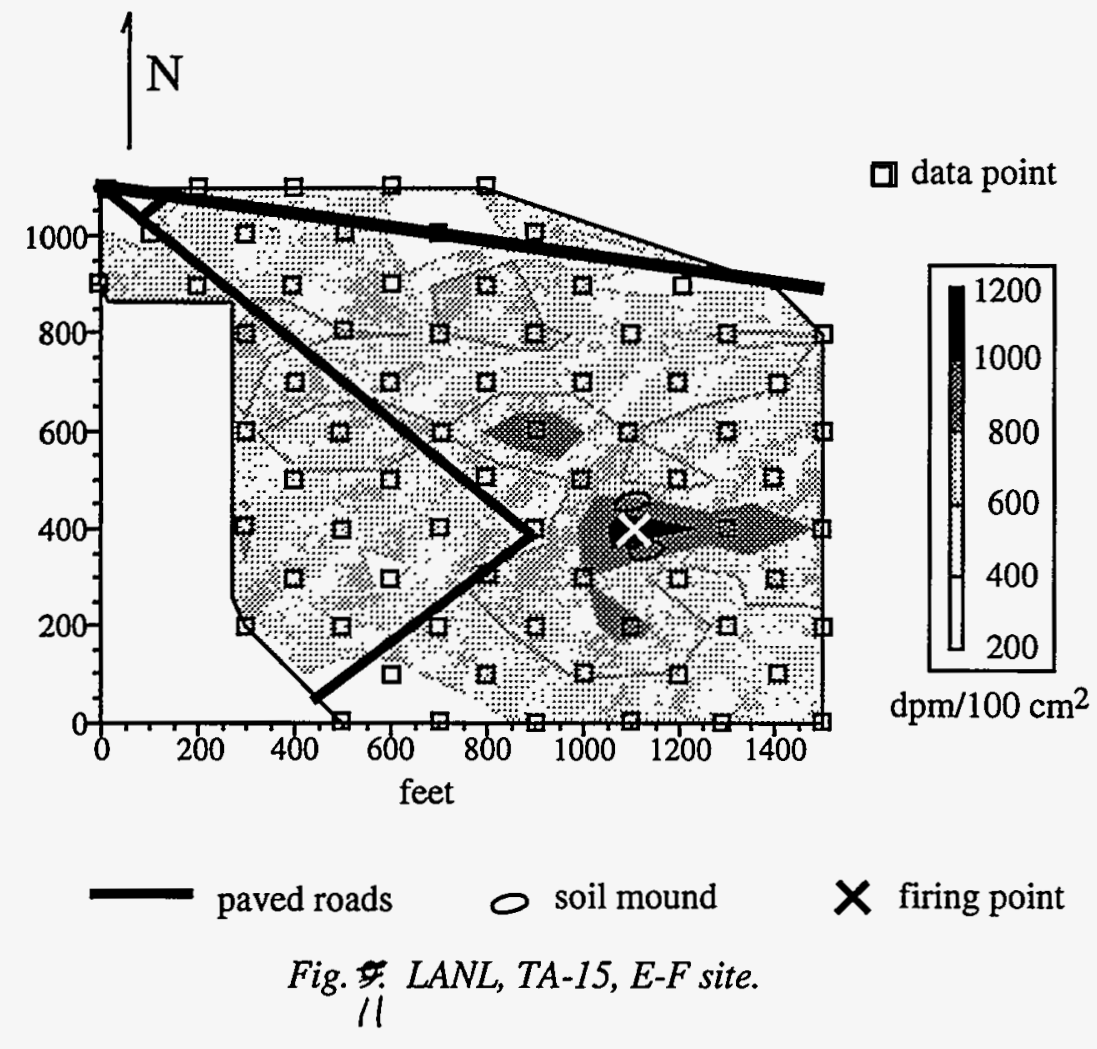




\section{SANDIA NATIONAL LABORATORIES}

\section{Site Description}

Sandia Sites 68 and 71 are part of SNL's Central Test Area ADS 1334. Site 68 was an old burn site where the effects of fire on weapons were investigated. Radioactive soil was removed from this area in a cleanup in the 1970s. Site 71 was a location where up to four dispersal tests using depleted uranium were conducted to measure how far nuclear-weapons material would be scattered by an accidental one-point detonation. Small catch pans were placed at certain distances from the firing point and the amount of uranium collected at each distance was measured. Depleted uranium was also used in these tests. A limited number of chemical explosive shots were fired there as well. The terrain is relatively flat in most areas. The most notable feature is an arroyo that runs east to west across the site. Any vegetation that would interfere with the detector's operation was removed with a weedeater-type trimmer prior to data acquisition. To generate a map of the contamination remaining in the area, a $200-\mathrm{ft}$ grid spacing was laid out by SNL personnel. The LSSM was used to obtain a measurement at each of 96 grid points and at each of 10 flagged "hot spots" at intermediate points.

\section{Results}

The results of the measurements are plotted in Figure 12. Readings at the flagged "hot spots" have been excluded in Fig. 12 because these represent hot point sources, not widespread contamination, and therefore would have changed the overall picture of the site.

\section{Interpretation}

The resulting computer picture is rather featureless: lower readings tend to clump together as do the higher readings, indicating general trends. At the measured levels, all activity could be attributed to variations in local background activity. The highest area of activity, which was in the northeast corner of the grid, may be due to a different soil or bedrock type. There was no evidence of widespread low-level contamination. The presence of hot spots off of the 96-point grid suggests a fragmentation problem as opposed to a fine dispersal problem.

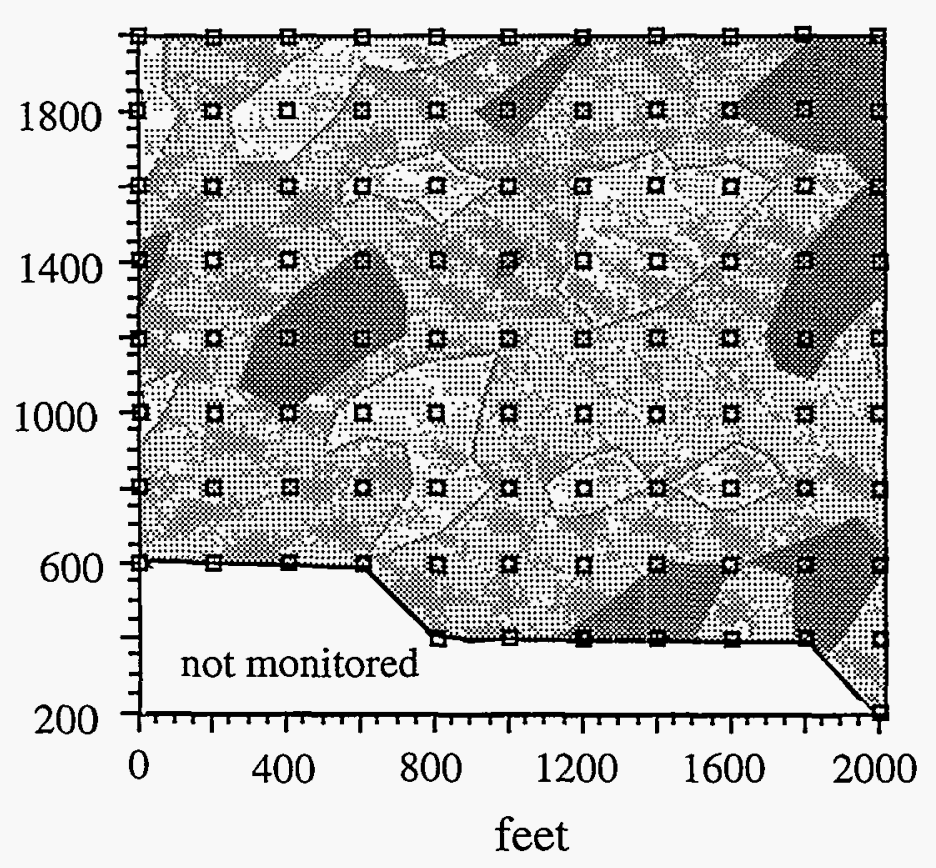

Fig. 12. SNL, Sites 68 and 71. $\square$ data point

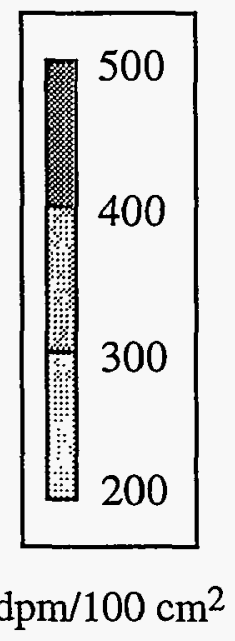




\section{LANL TA-49, AREA 1}

\section{Site Description}

LANL TA-49, the Frijoles Mesa Site, is inactive. Underground tests took place at Area 1 during the 1960s. Both uranium and plutonium were used in these shots. The topography of the site is like that of other firing sites at Los Alamos: flat, arid terrain covered with sparse grassy vegetation. The site is bounded by a fence; measurements were made on both sides of the fence for completeness. The data acquisition plan was straightforward: a grid with 25 -ft centers was laid out and the LSSM was placed over each data point. If any vegetation was present at a data point, it was trimmed with a weedeater-type trimmer and the clippings were removed.

\section{Results}

The LSSM required $\sim 10$ minutes per data point. The data collected were used to create Figure 13.

\section{Interpretation}

Figure 13 shows no contamination above background level.

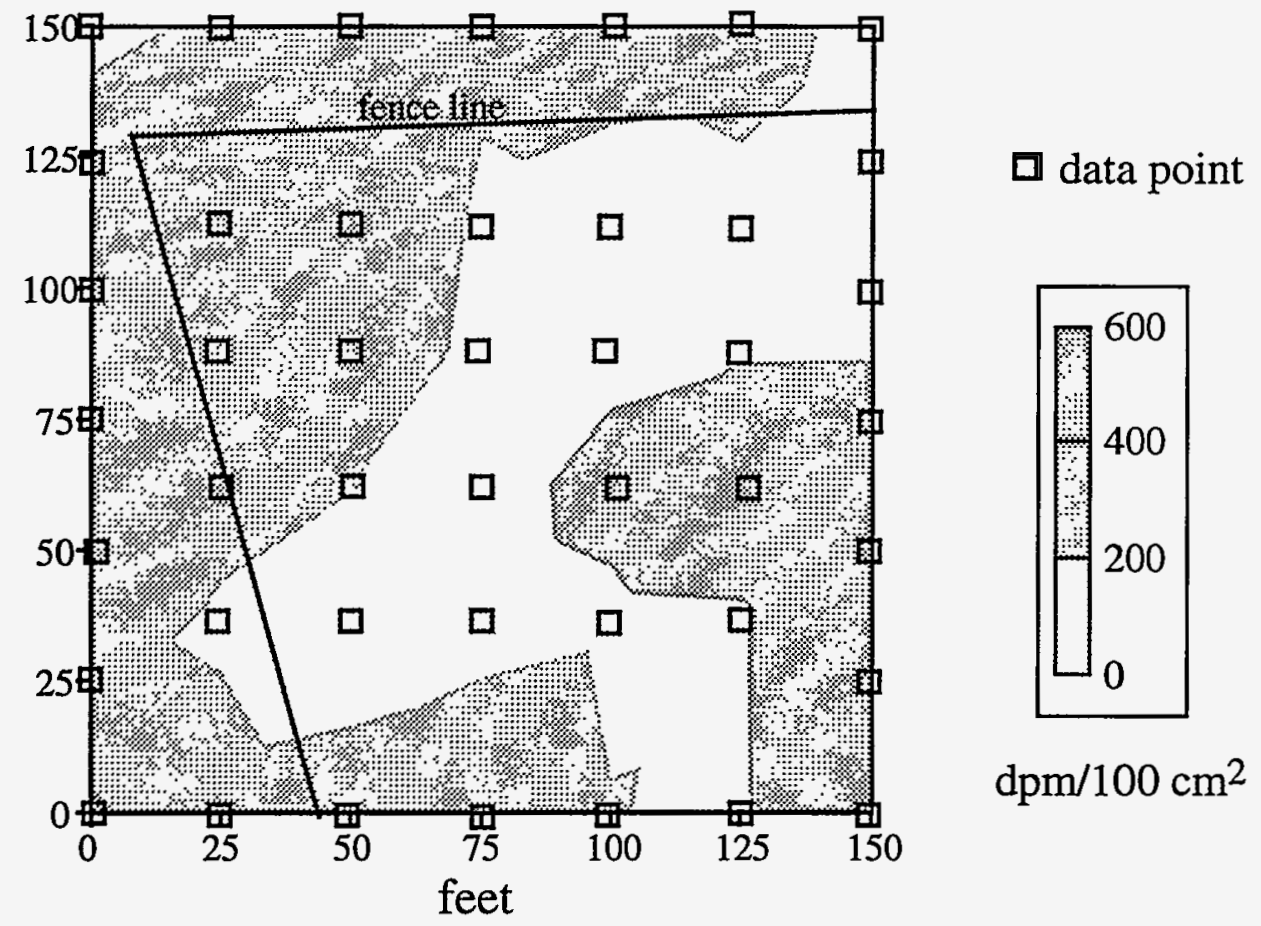

Fig. 13. LANL, TA-49, Area 1 . 


\section{LANL TA-49, AREA 11}

\section{Site Description}

Area 11 lies near Area 1 and is suspected of plutonium contamination. The site topography is like that of Area 1: flat, arid terrain with some grassy vegetation. A drainage ditch runs through the site as shown in Fig. 14. A grid pattern was laid out on the site with center points spaced every $25 \mathrm{ft}$. The LSSM monitored each data point. If vegetation was found on a data point, it was removed with a weedeater-type trimmer. Otherwise no preparation was done to the data points.

\section{Results}

The LSSM required $\sim 10$ minutes to acquire a sufficient data at each given data point. The resulting plot is shown in Fig. 14.

\section{Interpretation}

Area 11 showed considerably higher contamination than did Area 1. The area at one corner was significantly above the normal background variations at Los Alamos. There are no obvious geographical features that could explain the hotter area. Given the history of the site, further sampling would be prudent.

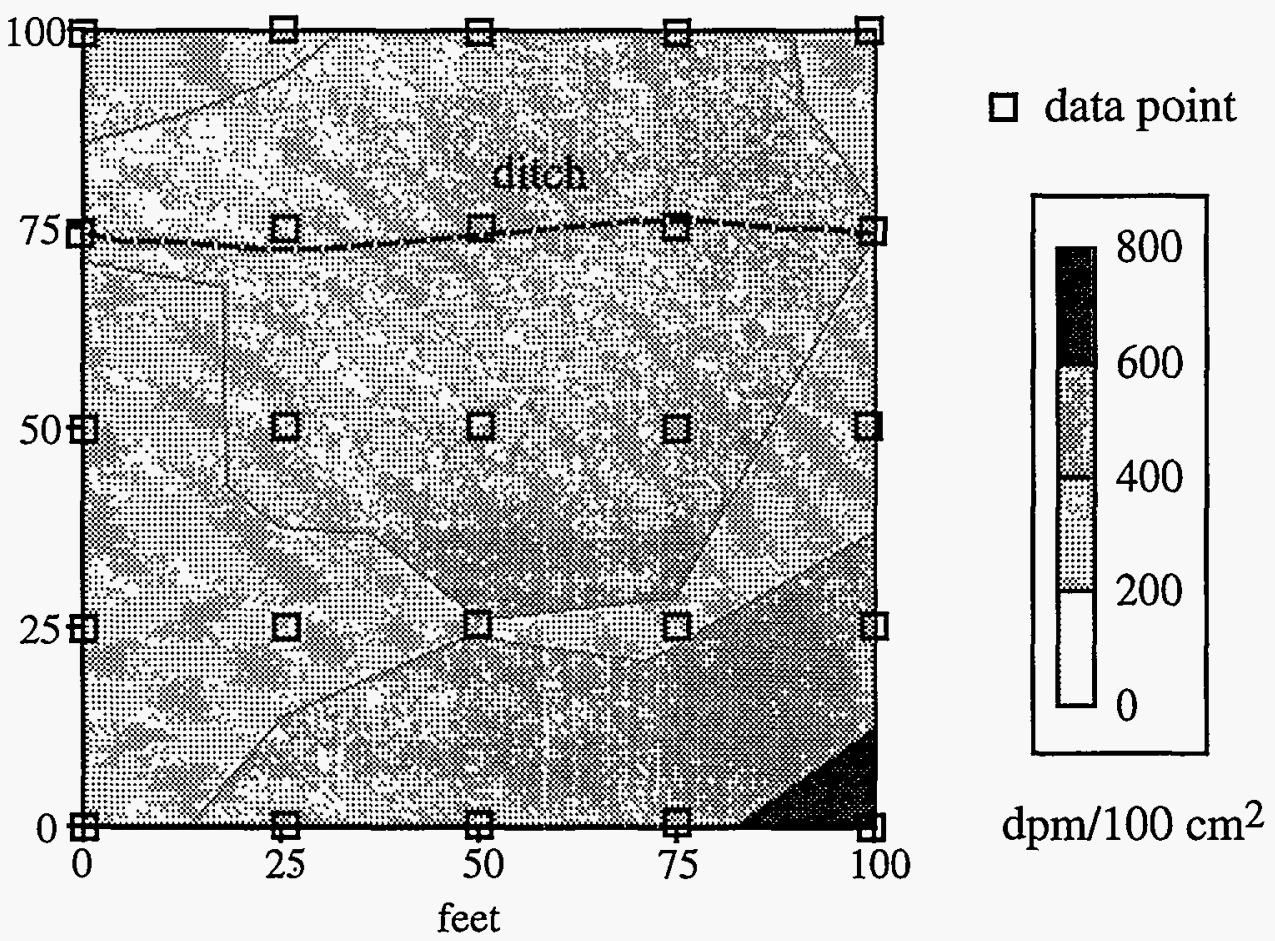

Fig. 14. LANL, TA-49, Area 11. 


\section{SUMMARY}

When uranium is dispersed in the air, it settles on the soil surface and, over a period of years, diffuses into the soil. Both Fernald and Los Alamos have shown that after several years the concentration falls off exponentially with depth down to background levels by about 12 in. in depth. The highest concentrations rest on the surface. Since the soil surface monitors measure just the top surface, they are more sensitive in finding low-level, widespread contamination than most other techniques, core sampling, for example. As long as there is not an overburden of fill dirt or gravel, normal biological processes and rain keep the surface soil churned up enough to make alpha monitoring effective. The success of the soil surface monitors in tracking contamination in former as well as active sites points to its usefulness as a characterization tool.

Start-up funding for the LRAD soil surface monitors was provided by the DOE Uranium in Soils Integrated Demonstration, which was hosted by the Fernald Environmental Management Corporation. Our task was to demonstrate LRAD as a new, real-time characterization technique. From that start, the LRAD soil surface monitors have been successfully fielded at over a dozen sites in their first two years. Their behavior is well understood, and any problems were fixed. They have been fielded successfully in both high and low temperatures as well as both high and low humidity. Technical expertise is not required for operation and analysis; nearly 20 people, ranging from those with no college experience to students to $\mathrm{Ph} . \mathrm{D}$.'s, have successfully operated the tractormounted LSSM. To these and other people who have contributed to this project, we offer our appreciation for a job well done. Soil surface monitors work.

\section{REFERENCES}

1. D. W. MacArthur, K. S. Allander, J. A. Bounds, R. W. Caress, M. M. Catlett, and D. A. Rutherford, "LRAD Surface Monitors," Los Alamos National Laboratory document LA12524-MS (1993).

2. C. F. V. Mason, K. S. Allander, J. A. Bounds, S. E. Garner, K. J. Walter, "The Use of the LongRange Alpha Detector (LRAD) for Alpha Emission Surveys at Active and Inactive Firing Sites," Los Alamos National Laboratory document LA-UR-94-400 (1994). 